\title{
Tacrolimus Improves the Implantation Rate in Patients with Elevated Th1/2 Helper Cell Ratio and Repeated Implantation Failure (RIF)
}

\section{Tacrolimus verbessert die Implantationsrate bei Patientinnen mit einem erhöhten Verhältnis von T-Helferzellen des Typs 1 zum Typ 2 und wiederholtem Implantationsversagen}

(C) 98

Authors

Zahra Bahrami-Asl ${ }^{1,2}$, Laya Farzadi ${ }^{3,4}$, Amir Fattahi ${ }^{3,4}$, Mehdi Yousefi ${ }^{5}$, Alicia Quinonero², Parvin Hakimi ${ }^{4}$, Zeinab Latifi $^{6}$, Hamid Reza Nejabati ${ }^{6}$, Tohid Ghasemnejad ${ }^{7}$, Aydin Raei Sadigh ${ }^{6}$, Mohammad Hassan Heidari ${ }^{1}$, Mohammad Nouri ${ }^{3,8}$, Marefat Ghaffari Novin ${ }^{1}$, Francisco Dominguez ${ }^{2}$

Affiliations

1 Department of Biology and Anatomical Sciences, School of Medicine, Shahid Beheshti University of Medical Sciences, Tehran, Iran

2 Fundacion Instituto Valenciano de Infertilidad (FIVI), Instituto Universitario IVI (IUIVI), ISS LaFe, Valencia, Spain

3 Department of Reproductive Biology, School of Advanced Medical Sciences, Tabriz University of Medical Sciences, Tabriz, Iran

4 Women's Reproductive Health Research Center, Tabriz University of Medical Sciences, Tabriz, Iran

5 Department of Immunology, Faculty of Medicine, Tabriz University of Medical Sciences, Tabriz, Iran

6 Department of Biochemistry and Clinical Laboratories, Faculty of Medicine, Tabriz University of Medical Sciences, Tabriz, Iran

7 Department of Medical Genetics, Faculty of Medicine, Tabriz University of Medical Sciences, Tabriz, Iran

8 Institute for Stem Cell and Regenerative Medicine, Tabriz University of Medical Sciences, Tabriz, Iran

\section{Key words}

repeated implantation failure, embryo implantation, tacrolimus, immune system, assisted reproductive technology (ART), intracytoplasmic sperm injection (ICSI), in vitro fertilization (IVF), leukemia inhibitory factor (LIF), interleukin (IL)-4, IL-10, IL-17, interferon gamma (IFN-Y)

\section{Schlüsselwörter}

wiederholtes Implantationsversagen, Embryotransfer, Tacrolimus, Immunsystem, assistierte Reproduktionstechnologie (ART), intrazytoplasmatische Spermieninjektion (ICSI), In-vitro-Fertilisation (IVF), leukämiehemmender Faktor (LIF), Interleukin (IL)-4, IL-10, IL-17, Interferon gamma (IFN- $\gamma$ ) received 19.9.2019

revised 24.10.2019

accepted 9.11.2019

Bibliography

DOI https://doi.org/10.1055/a-1056-3148

Geburtsh Frauenheilk 2020; 80: 851-862 @ Georg Thieme

Verlag KG Stuttgart · New York | ISSN 0016-5751

Correspondence

Marefat Ghaffari Novin

Department of Biology and Anatomical Sciences, School of Medicine, Shahid Beheshti University of Medical Sciences Parvaneh St., Chamran High Way, 19857-17443 Tehran, Iran mghaffarin@sbmu.ac.ir

Correspondence

Mohammad Nouri

Department of Reproductive Biology, Faculty of Advanced

Medical Sciences, Tabriz University of Medical Sciences

Golgasht Street, 5166/15731 Tabriz, Iran

nourimd@yahoo.com

\section{ABSTRACT}

Introduction An abnormal endometrial immune response is involved in the pathogenesis of repeated implantation failure (RIF), so we investigated the effectiveness of tacrolimus treatment on the endometrium of RIF patients.

Materials and Methods Ten RIF patients with elevated Thelper 1/T-helper 2 (Th1/Th2) cell ratios were recruited into a clinical study. The expression of p53, leukemia inhibitory factor (LIF), interleukin (IL)-4, IL-10, IL-17, and interferon gamma (IFN- $\mathrm{Y})$ in the endometrium of patients with and without tacrolimus treatment and the association of these factors with assisted reproductive technology (ART) outcomes were investigated. 
Results Tacrolimus significantly increased the expression of LIF, IL-10, and IL-17 and decreased the expression of IL-4, IFN- $\gamma$, and the IFN- $\gamma /$ IL-10 ratio in RIF patients. Tacrolimus treatment resulted in an implantation rate of $40 \%$, a clinical pregnancy rate of $50 \%$, and a live birth rate of $35 \%$ in RIF patients with elevated Th1/Th2 ratios who had previously failed to become pregnant despite at least three transfers of embryos. We also found a significant positive correlation between IL-10 levels and the implantation rate.

Conclusions Our findings suggest that RIF patients with a higher Th1/Th2 ratio could be candidates for tacrolimus therapy and that this immunosuppressive drug could be acting through upregulation of LIF, IL-10, and IL-17.

\section{ZUSAMMENFASSUNG}

Einleitung Da eine abnorme Immunantwort des Endometriums möglicherweise an der Pathogenese von wiederholtem Implantationsversagen (RIF) beteiligt ist, haben wir die Auswirkungen einer Tacrolimus-Behandlung auf das Endometrium von Patientinnen mit RIF untersucht.

Material und Methoden Eine klinische Studie wurde bei 10 RIF-Patientinnen mit einem erhöhten Verhältnis der T-Helferzellen des Typs 1 zum Typ 2 (Th1/Th2) durchgeführt. Alle in der Studie aufgenommenen Frauen hatten mindestens 3 er- folglose Implantationsversuche hinter sich. Die Exprimierung von p53, leukämiehemmendem Faktor (LIF), Interleukin (IL)4, IL-10, IL-17 und Interferon gamma (IFN- $\gamma$ ) in der Gebärmutterschleimhaut dieser Patientinnen vor und nach der Behandlung mit Tacrolimus und der Zusammenhang zwischen diesen Faktoren und dem Outcome nach assistierten Reproduktionstechnologien (ART) wurden geprüft.

Ergebnisse Die Behandlung mit Tacrolimus führte zu einer signifikanten Steigerung der Exprimierung von LIF, IL-10 und IL-17, verringerte die Exprimierung von IL-4 und IFN- $\gamma$ und senkte das Verhältnis von IFN-y zu IL-10 bei Patientinnen mit RIF. Die Tacrolimus-Behandlung führte zu einer Implantationsrate von $40 \%$, einer $50 \%$ igen klinischen Schwangerschaftsrate und einer Lebendgeburtentrate von 35\% bei Patientinnen mit RIF und einem erhöhten Th1/Th2-Verhältnis. Es gab auch eine signifikante positive Korrelation zwischen den IL-10-Konzentrationen und der Implantationsrate.

Schlussfolgerungen Unsere Ergebnisse lassen darauf schließen, dass RIF-Patientinnen mit einem erhöhten Th1/ Th2-Verhältnis geeignete Kandidaten für eine Behandlung mit Tacrolimus sein könnten und dass dieses Immunsuppressivum möglicherweise durch eine Hochregulierung von LIF, IL10 und IL-17 seine Wirkung entfaltet.

\section{Introduction}

While assisted reproductive technology (ART) has made considerable advances in the decades since its inception, the current success rate is still under $30 \%$ [1] and implantation failure remains a significant obstacle [2]. Repeated implantation failure (RIF) is diagnosed when a woman under the age of 40 is unable to achieve a pregnancy after the transfer of at least three good-quality embryos over a minimum of three fresh or frozen cycles [3]. Dysregulation of the endometrial immune profile results in a decrease in endometrial receptivity and is thought to be responsible for the failure of embryo implantation $[2,4,5]$. It has been reported that endometrial immune profiles appear to be dysregulated in $81.7 \%$ of RIF patients. Studies have demonstrated an overactivation of the immune system in $56.6 \%$ and low activation in $25 \%$ of RIF patients [2]. Thus, resolving this mechanism may improve the success rates for RIF patients.

During the window of implantation (WOI), a massive influx of immune cells induces maternal immune tolerance to protect the embryo from rejection [6]. Immune cells such as T-helper cells (Th1, Th2, and Th17) and regulatory T-cells (Treg) contribute to maternal immune tolerance and the precise balance of cytokine signals needed to maintain pregnancy [7]. Th1 cells, which contribute to cell-mediated immunity, produce inflammatory cytokines such as interleukin-2 (IL-2), interferon gamma (IFN- $-\gamma$ ), and tumor necrosis factor-alpha (TNF- $\alpha$ ), while Th2 cells are a source of anti-inflammatory cytokines such as IL-4 and IL-10 which contribute to humoral responses. Successful implantation shifts the response of the endometrial lining from a cell-mediated to a humoral response, but an imbalance between Th1 and Th2 cells and their cytokines can result in implantation failure [4]. Pro- and anti-inflammatory cytokine ratios in peripheral blood which reflect the Th1/Th2 ratio (e.g., IFN-y/IL-4 and IFN- $/ /$ IL-10) are significantly higher in RIF patients compared to fertile controls $[4,8,9]$. Th2 cytokines such as IL-4 can induce the expression of leukemia inhibitory factor (LIF) [10], a pro-inflammatory cytokine essential for blastocyst implantation and stromal decidualization [11]. The tumor suppressor p53 plays a crucial role in maintaining genomic stability and for tumor prevention [12]. Furthermore, p53 plays a role regulating maternal reproduction through regulation of LIF gene expression [13]. An embryo carries both paternal and maternal antigens, and embryo implantation is considered an allograft [14]. It has been proved that Th17 cells contribute to allograft rejection $[15,16]$, and it has been demonstrated that the RIF mechanism is similar to that of allograft rejection. During the transient immune switch, $65-70 \%$ of the immune cells are uterine natural killer (uNK) cells in the endometrium that belong to the innate immunity compartment [17]. The activation of these cells plays a fundamental role in Th2 cytokine production and the establishment of local maternal tolerance [18]. Interestingly, it has been demonstrated that the endometrium of women with RIF contains abnormal levels of uNK cells [19]. Regulation of the immune system by therapeutic agents may improve implantation and pregnancy rates in women with a history of RIF. Nakagawa et al. $[4,8]$ demonstrated that when RIF patients with an elevated Th1/Th2 ratio were treated with tacrolimus, an immune-suppressive agent, the pregnancy rate increased significantly compared to a nontreated group. Tacrolimus is a T-cell-specific, anti-inflammatory agent [20] that suppresses the immunological rejection of an allograft and promotes its survival by inhibiting lymphocyte prolifera- 
tion [21]. Moreover, it has been documented that tacrolimus inhibits the transcription and release of both Th1 and Th2 cytokines, such as IL-2, IL-4, IL-5, IFN- $y$, and TNF- $\alpha$ [22], but primarily suppresses Th1 cells [8]. Tacrolimus can also inhibit the expression of IL-17 and induce the expression of both p53 and LIF, reducing allograft rejection $[15,16,22-26]$.

Given the involvement of tacrolimus in immune regulation, we investigated the effect of tacrolimus treatment on endometrial immune response, as well as endometrial receptivity markers in RIF patients. To do this, we evaluated protein and mRNA expression of p53, LIF, IL-4, IL-10, IL-17, and IFN-y in the endometrium of RIF patients with and without tacrolimus treatment and also investigated the association between these factors and ART outcomes. To our knowledge, this is the first study to investigate the effects of tacrolimus on the cytokine expression profile and endometrial receptivity markers in RIF patients.

\section{Materials and Methods}

The study was carried out at the Infertility and IVF division of ALZahra Hospital at the Tabriz University of Medical Sciences in Tabriz, Iran from May 2017 to December 2018 in collaboration with the Department of Reproductive Biology at the Shahid Beheshti University of Medical Sciences in Tehran, Iran. This study was approved by the Research Ethics Committee of the Shahid Beheshti University of Medical Sciences (approval code: IR. SBMU. MSP. REC.1395.580). The study was carried out in accordance with the Code of Ethics of the World Medical Association (Declaration of Helsinki), and a signed informed consent form was obtained from all patients prior to entering the study. The study has been registered in the Iranian Registry of Clinical Trials (https://www.irct.ir; Registry code: IRCT20171007036623N1).

\section{Study population}

Ten women diagnosed with RIF and eligible for intracytoplasmic sperm injection (ICIS)/embryo transfer (ET), were selected for participation. Each participant also had a history of three or more failed ART cycles with morphologically good-quality embryos. Patients were assessed by transvaginal ultrasound, hysterosalpingography, and hysteroscopy before they were entered in the study to exclude patients with submucosal fibroids, endometrial polyps, intrauterine adhesions, congenital anomalies of the uterus, and/or hydrosalpinges. Furthermore, none of the participants had any history of autoimmune disease. Women with a history of chronic inflammatory conditions, acquired or inherited thrombophilia, previous immunotherapy, previous miscarriage, irregular menstrual cycles, or who were vaccinated in the last three months were excluded from the study. To determine the presence of immunological disorders, IFN-y and IL-4 levels were measured on days 5-10 of the menstrual cycle and an IFN-y/IL-4 ratio $\geq 10.3$ was classified as an elevated Th1/Th2 ratio [4]. These patients were recruited into the study. A schema of the in-vivo study design is presented in $\mathbf{r}$ Fig. $\mathbf{1}$.

To determine the baseline Th1/Th2 ratio, $10 \mathrm{~mL}$ of venous blood was collected into sodium heparinized tubes on days 5-10 of the menstrual cycle. Th1 and Th2 cells were determined by detecting intracellular interferon (IFN)- $y$ and IL-4 production. Periph-

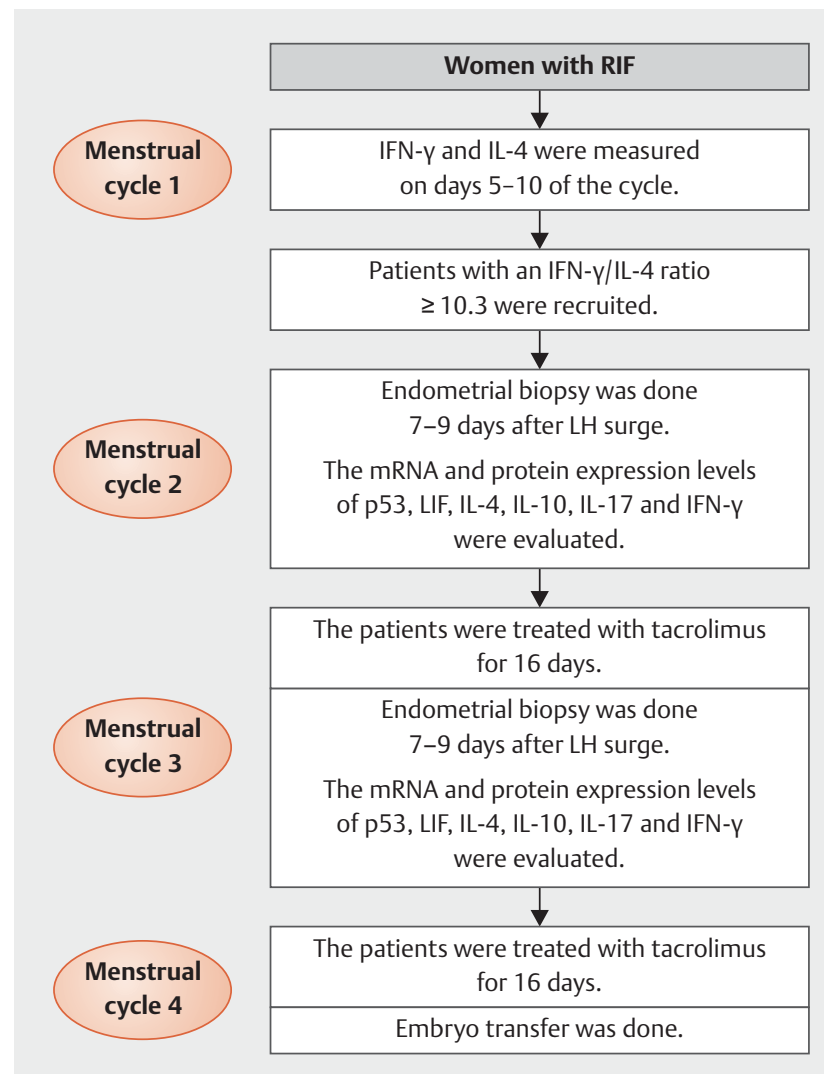

> Fig. 1 Schema of the in-vivo study design. RIF: repeated implantation failure, IFN-Y: interferon gamma, IL: interleukin, LH: luteinizing hormone, LIF: leukemia inhibitory factor.

eral blood mononuclear cells (PBMCs) were isolated from blood samples by adding $1.077 \mathrm{~g} / \mathrm{mL}$ of ficoll (Lymphosep, Biosera, UK) followed by centrifugation. Before flow cytometry, samples were incubated with $10 \mathrm{ng} / \mathrm{mL}$ of phorbol 12-myristate 13-acetate (PMA) and $0.5 \mathrm{mM}$ ionomycin at $37^{\circ} \mathrm{C}$ in a $5 \% \mathrm{CO}_{2}$ humidified incubator for $5 \mathrm{~h}$. Chemical stimulators such as monensin (eBioscience, San Diego, CA, USA) were used to improve the staining of intracellular cytokines. Before staining, cells were washed and incubated with monoclonal antibodies including anti-CD4-APC (BD Biosciences), fluorescein isothiocyanate (FITC)-labeled antiIFN-y (Becton Dickinson, Franklin Lakes, NJ, USA), and anti-IL-4phycoerythrin (PE) (Becton Dickinson). Th1 and Th2 cells were detected among PBMCs using the BD FACSCalibur ${ }^{\mathrm{TM}}$ flow cytometer (San Jose, CA, USA). Th1 cells were defined as CD4+ lymphocytes with intracellular IFN-y but without IL-4. Th2 cells were detected as CD4+ lymphocytes with intracellular IL-4 but without IFN-Y. The ratio of IFN- $y$ to IL-4 positive Th cells was expressed as the Th1/Th2 ratio.

\section{Controlled ovarian stimulation and embryo transfer (ET)}

Applied ovarian stimulation was completed as follows: According to the age and ovarian reserve of patients, 150-225 IU of rFSH (Gonal-F, Merck Serono, Tokyo, Japan) was administered on day 2 
or 3 of the menstrual cycle. Follicular growth was assessed by transvaginal sonography. When follicles reached $12-13 \mathrm{~mm}$ in diameter, 0.25 mg/day of GnRH antagonist (Cetrotide, Merck Serono, Darmstadt, Germany) and $75 \mathrm{IU} /$ day of human menopausal gonadotropin ([hMG], Menopur, Ferring, Switzerland) was administered until at least one follicle reached a diameter of $17-18 \mathrm{~mm}$. At this point, $10000 \mathrm{IU}$ hCG (Pregnyl, Merck Serono) was injected and ovum pick-up (OPU) was performed 34-36 hours later. Intracytoplasmic sperm injection (ICSI) was utilized for all patients. For luteal phase support, hormone replacement cycle (HRC) was used, starting with the administration of an oral contraceptive (Ovocept-HD, Abureihan Co., Iran) and a GnRH agonist (Diphereline $3.75 \mathrm{mg}$, Ipsen, France), and in the next cycle, treatment was continued with conjugated estrogens $(1.25 \mathrm{mg}$ equilenin, Grupo Ferrer Internacional SA, Spain) until an appropriate endometrial thickness was achieved (at least $7 \mathrm{~mm}$ under transvaginal sonography). Frozen ET was performed on day 19-21 of the menstrual cycle and all patients received two morphologically good quality blastocysts. From the day of ET until pregnancy testing, patients were treated with Cyclogest ${ }^{\circledR}$ (400 mg pessary, Actoverco, Karaj, Iran). A biochemical pregnancy test was performed 14 days after ET. Clinical pregnancy was recognized when the development of a gestational sac was detected on transvaginal ultrasound 21 days after ET. Ongoing pregnancy was recognized when a normal fetus was seen on transvaginal ultrasound at 12 weeks of gestation. The primary and secondary endpoints were clinical pregnancy and ongoing pregnancy, respectively.

\section{Tacrolimus treatment}

Patients were treated with two cycles of tacrolimus (Prograf, Astellas Pharma Ltd, Staines, UK), one for the endometrial biopsy (second endometrial biopsy) and one for the embryo transfer. In the first treatment cycle, patients were treated with tacrolimus for 16 days before undergoing endometrial biopsy. Similarly, in the second treatment cycle, we administrated tacrolimus for 16 days (two days before ET and up to 14 days after ET). The daily dosage of tacrolimus was $1-3 \mathrm{mg}$, depending on the degree of Th1/Th2 elevation; patients with a mild increase in the Th1/Th2 ratio ( $\geq 10.3$ and $<13.0$ ) were treated with $1 \mathrm{mg}$ of tacrolimus, patients with a moderate increase in the Th1/Th2 ratio ( $\geq 13.0$ and $<15.8$ ) were treated with $2 \mathrm{mg}$ of tacrolimus, and patients with high increase in the Th1/Th2 ratio $(\geq 15.8)$ were treated with $3 \mathrm{mg}$ of tacrolimus.

\section{Steroid hormone evaluation}

Serum estradiol and progesterone were evaluated using commercial ELISA kits (MyBioSource, San Diego, USA) according to the manufacturer's instructions. Both hormones were analyzed in cycles with and without tacrolimus treatment 7 to 9 days after the $\mathrm{LH}$ surge.

\section{Endometrial biopsy}

The endometrium was gently aspirated by rotating a Pipelle de Cornier (Laboratoire CCD, Paris, France) in the endometrial cavity during the window of implantation $(\mathrm{LH}+7$ to $\mathrm{LH}+9)$ in two different consecutive cycles. The Pipelle contents were emptied onto a gauze compress and divided into two parts, one of which was placed in $4 \%$ formaldehyde for routine evaluation, endometrial dating, and CD56 immunolabeling. The second part was placed in RNAlater ${ }^{\mathrm{TM}}$ stabilization solution for molecular analysis. A urinary LH kit (Abon Biopharma Company, China) was used to determine the day of the LH surge. Twenty samples of endometrial tissue from 10 patients were obtained in two subsequent menstrual cycles with and without tacrolimus treatment. The first biopsy was done in a cycle without treatment and the other biopsy in a second cycle with tacrolimus treatment. Samples were histologically assessed to match the secretory phase based on the appearance of tortuous glands, enlarged stromal cells, and the presence of subnuclear cytoplasmic glycogen vacuoles in the lumen of the glands. Data from one patient was excluded due to non-histocompatibility with secretory phase features. Endometrial samples were used to evaluate the protein and mRNA levels of cytokines using immunohistochemistry and real time-PCR techniques, respectively.

\section{mRNA expression of p53, LIF, IL-4, IL-10, IL-17, and IFN-Y}

Total RNA was extracted from 20 endometrial tissues obtained from ten RIF patients using an RNeasy Plus Kit (QIAGEN, USA) according to the manufacturer's instructions. The concentration of each RNA sample was measured using a NanoDrop 2000 Spectrophotometer (ND-1000, NanoDrop technology, Australia). Complementary DNA (cDNA) was synthesized using a PrimerScript RT reagent kit (Takara Bio, Otsu, Japan). SYBR Green was employed for the analysis of p53, LIF, IL-4, IL-10, IL-17, and IFN-y expression. Sequences of the study primer sequences are summarized in - Table 1. In the PCR program, after $2 \mathrm{~min}$ at $50^{\circ} \mathrm{C}$ and $2 \mathrm{~min}$ at $95^{\circ} \mathrm{C}$ as an activation step, 40 cycles comprised of $15 \mathrm{~s}$ denaturation at $95^{\circ} \mathrm{C}, 15 \mathrm{~s}$ annealing at $60^{\circ} \mathrm{C}$, and extension at $72^{\circ} \mathrm{C}$ for 1 min were performed using a StepOnePlus real-time PCR system (Applied Biosystems, Fisher Scientific, US). Gene expression was analyzed by comparison to a reference gene in each PCR run. Relative gene expression levels were calculated using the $2^{-\Delta \Delta C t}$ method and expressed as a fold change of the control sample. All reactions were performed in triplicate.

\section{Protein expression of LIF, IL-4, IL-10, IL-17, and IFN-Y}

One part of the endometrial biopsies was immediately placed into $10 \%$ neutral buffered formalin for overnight fixation and then embedded in paraffin wax. LIF, IFN- $\gamma$, IL-4, IL-10, and IL-17 protein expression as well as CD56+ cells (uNK cells) were determined using fluorescent immunohistochemistry. Endometrial sections with a thickness of $5 \mu \mathrm{m}$ were fixed with $4 \%$ paraformaldehyde in PBS $(\mathrm{pH} 7.4)$ for $20 \mathrm{~min}$ and permeabilized by $0.3 \%$ Triton X100 for 30 min and blocked in 10\% normal goat serum in phosphate-buffered saline (PBS) for $1 \mathrm{~h}$ at room temperature. Samples were incubated overnight at $4{ }^{\circ} \mathrm{C}$ with the corresponding primary antibodies for LIF (ab113262, Abcam, Cambridge, UK), IFN-ץ (ab25101, Abcam), IL-4 (ab2503, Abcam), IL-10 (ab34843, Abcam), and IL-17 (ab79056, Abcam) diluted in PBS. Samples were then incubated with FITC-conjugated secondary antibody (ab6717, Abcam) diluted with PBS at room temperature and kept in the dark for $1 \mathrm{~h}$. Sections were subsequently mounted with 4'6-diamidino-2'-phenylindole dihydrochloride (DAPI, Roche Di- 
- Table 1 Primer sequences for real-time PCR.

\begin{tabular}{|c|c|c|c|c|}
\hline & & Sequence $\left(5^{\prime} \rightarrow 3^{\prime}\right)$ & $\operatorname{TM}\left({ }^{\circ} \mathrm{C}\right)$ & Product size (bp) \\
\hline \multirow[t]{2}{*}{ TP53 } & Forward & AGCCACATTCTAGGTAGGGGC & 61.78 & \multirow[t]{2}{*}{130} \\
\hline & Reverse & TGCACTCTGTGAGGTAGGTGC & 61.78 & \\
\hline \multirow[t]{2}{*}{ LIF } & Forward & GAAGCTGGGCTGTCAACTCCT & 61.78 & \multirow[t]{2}{*}{99} \\
\hline & Reverse & CCTCGGTTCACAGCACACTTC & 61.78 & \\
\hline \multirow[t]{2}{*}{ IL-10 } & Forward & ТССССТАAССТСАТTССССАA & 59.82 & \multirow[t]{2}{*}{90} \\
\hline & Reverse & GCCCGGCCTAGAACCAAATTT & 59.82 & \\
\hline \multirow[t]{2}{*}{ IL-17 } & Forward & CCGGCTGGAGAAGATACTGGT & 61.78 & \multirow[t]{2}{*}{126} \\
\hline & Reverse & CTGGGTCGGCTCTCCATAGTC & 63.73 & \\
\hline \multirow[t]{2}{*}{ IL-4 } & Forward & GCTGATCCGATTCCTGAAA & 54.51 & \multirow[t]{2}{*}{89} \\
\hline & Reverse & TACTCTGGTTGGCTTCCT & 53.69 & \\
\hline \multirow[t]{2}{*}{ IFN-y } & Forward & CTTTAAAGATGACCAGAGCATCCA & 59.30 & \multirow[t]{2}{*}{94} \\
\hline & Reverse & ATCTCGTTTCTTTTTTGTTGCTATTGA & 56.92 & \\
\hline \multirow[t]{2}{*}{$\beta$-actin } & Forward & GCATGGGTCAGAAGGATTCCT & 61.88 & \multirow[t]{2}{*}{106} \\
\hline & Reverse & TCGTCCCAGTTGGTGACG & 61.83 & \\
\hline
\end{tabular}

LIF: leukemia inhibitory factor, IL-10: interleukin-10, IL-17: interleukin-17, IL-4: interleukin-4, IFN-ץ: interferon gamma, $\beta$-actin: beta-actin

agnostics, Germany) to stain the nuclei and preserve fluorescence signals. Fluorescent signals were analyzed with fluorescence microscopy (Olympus BX51, Olympus Optical Co., Tokyo, Japan). For each patient, endometrial tissue samples were analyzed in triplicate. Triplicate tissue was a serial section from the same paraffin tissue block. All samples were imaged using a $400 \times$ objective lens.

\section{Immunohistochemistry of uterine NK cells}

Immunohistochemistry (IHC) with pre-diluted anti-CD56 (clone 123C3) mouse monoclonal primary antibody (Ventana Medical Systems, Roche Diagnostics, Germany) was performed on twenty endometrial biopsies obtained from ten RIF patients to detect uterine NK cells (uNKs). CD56-positive cells were counted per one $\mathrm{mm}^{2}$ of the tissue slide. Images were taken and prepared with an on-board camera (Cyber-Shot, Zeiss, Japan). Scale bars were produced using a morphometric lens ( $\mathrm{CH}-2$, Olympus, Germany) and proofed with Meazure software (C Thing Software, Sunnyvale, CA, USA). All images were captured under $100 \times$ magnification. Pixel-based frequency values were obtained using Image-Pro-insight software (Version 9.0, Media Cybernetics, USA).

\section{Statistical analysis}

Statistical analysis was performed using SPSS-PC statistics software (version 23; SPSS Inc., Chicago, IL, USA). Since the study data were normally distributed, paired t-test and student's t-test were applied to compare data before and after tacrolimus treatment and between pregnant and non-pregnant patients, respectively. Because of the normality of distribution, we used Pearson or Spearman tests to evaluate correlation. A p-value $<0.05$ was considered statistically significant.

\section{Results}

\section{Patient hormone levels}

Estradiol and progesterone levels in peripheral blood were measured on days 7-9 after the LH surge in cycles with and without tacrolimus treatment. Both estradiol (125.70 \pm 74.13 vs. $117.46 \pm 91.86 \mathrm{pg} / \mathrm{ml}, \mathrm{p}=0.84)$ and progesterone $(5.21 \pm 3.29$ vs. $3.90 \pm 2.58 \mathrm{ng} / \mathrm{ml}, \mathrm{p}=0.36$ ) were lower in the cycle with tacrolimus treatment compared to the cycle without tacrolimus. However, the differences did not reach statistical significance.

\section{mRNA and protein expression of endometrial markers in endometrial samples}

The expression of IL-4, IL-10, IL-17, IFN- $y$, LIF, and p53 mRNA in the endometrial samples was not statistically different with and without tacrolimus treatment ( $\triangleright$ Fig. 2 a). Although the expression of IL-10, IL-17, and p53 decreased following tacrolimus treatment, statistical significance was not reached $(p>0.05)$. The expression ratios of IFN- $\gamma /$ IL-4 and IFN- $/$ /IL-10 also did not show a significant change following tacrolimus treatment $(p>0.05$,

\section{- Fig. 2 a).}

In the cycle without tacrolimus treatment, positive correlations were found between p53 and LIF, IL-10, IL-17, IFN- $\gamma$, and the IFN$\mathrm{Y} / \mathrm{IL}-4$ ratio $\left(r_{\mathrm{s}}=0.793,0.794,0.937,0.694\right.$, and 0.772 , respectively). LIF mRNA was positively correlated with IL-10 and IL-17 expression ( $r_{s}=0.716$ and 0.896 , respectively). Furthermore, IL-10 expression showed positive correlations with IL-17 and IFN-y expression as well as with the IFN- $/$ /IL-4 ratio in the cycle without tacrolimus treatment $\left(r_{s}=0.872,0.816\right.$, and 0.857 , respectively). IL-17 expression was positively correlated with the IFN- $\mathrm{Y} / \mathrm{IL}-4$ ratio $\left(p=0.032\right.$ and $\left.r_{s}=0.712\right)$. In the cycle with tacrolimus treatment, we observed positive correlations between p53 and LIF and IL-17 
expression ( $r_{s}=0.972$ and 0.885 , respectively). IL-4 was significantly correlated with IFN- $y$ in the treated cycle $\left(r_{s}=0.812\right)$.

Protein expressions of endometrial IL-4, IL-10, IL-17, IFN- $\gamma$, and LIF in the cycles with and without tacrolimus treatment are illustrated in $>$ Fig. $\mathbf{2 b}$ b. Significant decreases in IL-4 and IFN-y protein, as well as a decrease in the IFN- $\mathrm{Y} / \mathrm{IL}-10$ ratio, were observed following tacrolimus administration ( $p<0.05)$. IL-10, IL-17, and LIF protein were significantly higher in the endometrial tissues treated with tacrolimus than those without treatment $(p<0.05$,

- Fig. 2 b).

Without tacrolimus treatment, a negative correlation was found between IL-10 and the IFN- $\mathrm{y} / \mathrm{IL}-10$ ratio $\left(\mathrm{r}_{\mathrm{s}}=-0.875\right)$. Also, IFN- $\gamma$ protein was positively correlated with IFN- $\mathrm{\gamma} / \mathrm{IL}-4$ and IFN- $\mathrm{\gamma}$ | IL-10 ratios ( $r_{s}=0.851$ and 0.795 , respectively). Similarly, with tacrolimus treatment, a negative correlation between IL-10 and the IFN- $\gamma /$ IL-10 ratio $\left(r_{s}=-0.718\right)$ was observed, while positive correlations between IFN- $\gamma$ and the IFN- $\gamma /$ IL-4 and IFN- $-/$ IL-10 ratios were observed ( $r_{\mathrm{s}}=0.835$ and 0.866 , respectively).

\section{Protein and mRNA levels of endometrial markers in pregnant and non-pregnant women}

Cytokine mRNA and protein levels were compared in pregnant and non-pregnant women ( $\triangleright \mathbf{F i g . 3} \mathbf{a}$ and $\mathbf{b}$, respectively). There was no significant difference in mRNA ( $\bullet$ Fig. $\mathbf{3 a}$ ) and protein ( $\triangleright$ Fig.3b) expression between pregnant and non-pregnant women with tacrolimus treatment $(p>0.05)$.

We also compared mRNA and protein levels in the previous cycle (without tacrolimus treatment) in pregnant and non-pregnant participants. The mRNA expression of IL-4 and IFN- $\gamma$ was significantly higher in the endometrial tissue of pregnant compared to non-pregnant women in the cycle without treatment $(p=0.03$ and 0.05 , respectively). Protein levels did not show any significant difference between pregnant and non-pregnant patients.
The mRNA expression of IL-4, IL-10, IL-17, IFN- $\gamma$, LIF, and p53, as well as the IFN- $/$ /IL-4 and IFN- $/ /$ IL-10 ratios in endometrial tissues on days 7-9 after the LH surge did not have a significant association with the implantation rate ( $\bullet$ Table 2 ). However, there was a significant positive correlation between IL-10 protein levels and implantation rates $(p=0.03$, $>$ Table 2$)$.

\section{Tacrolimus treatment improved RIF patient outcomes}

Embryo transfer was carried out in ten patients who received tacrolimus. The treatment resulted in an implantation rate of $40 \%$, a clinical pregnancy rate of $50 \%$ and a live birth rate of $35 \%$ in RIF patients with elevated Th1/Th2 ratios who had previously failed to become pregnant after at least three separate embryo transfers.

\section{Effect of tacrolimus on uNK in endometrial tissue}

The number of uNK cells was higher in the cycle without tacrolimus treatment compared to the cycle with tacrolimus; however, this difference did not reach statistical significance $(p=0.06$, - Fig. 4a). We did not find a difference in uNK cell counts between pregnant and non-pregnant women ( $p>0.05$, > Fig. 4 b).

\section{Discussion}

Given the ability of tacrolimus to increase implantation and pregnancy rates in RIF patients with an elevated Th1/Th2 ratio $[4,8]$, the effects of tacrolimus administration on the expression of endometrial factors ( $p 53$, LIF, IFN- $\gamma$, IL-4, IL-10, and IL-17) were assessed along with ART outcomes in RIF patients. The in-vitro expression of these factors in human endometrial epithelium cells (EECs) and endometrial stromal cells (ESCs) after treatment with different doses of tacrolimus was also assessed.

Endometrial LIF protein levels increased significantly after treatment with tacrolimus. To the best of our knowledge, this is

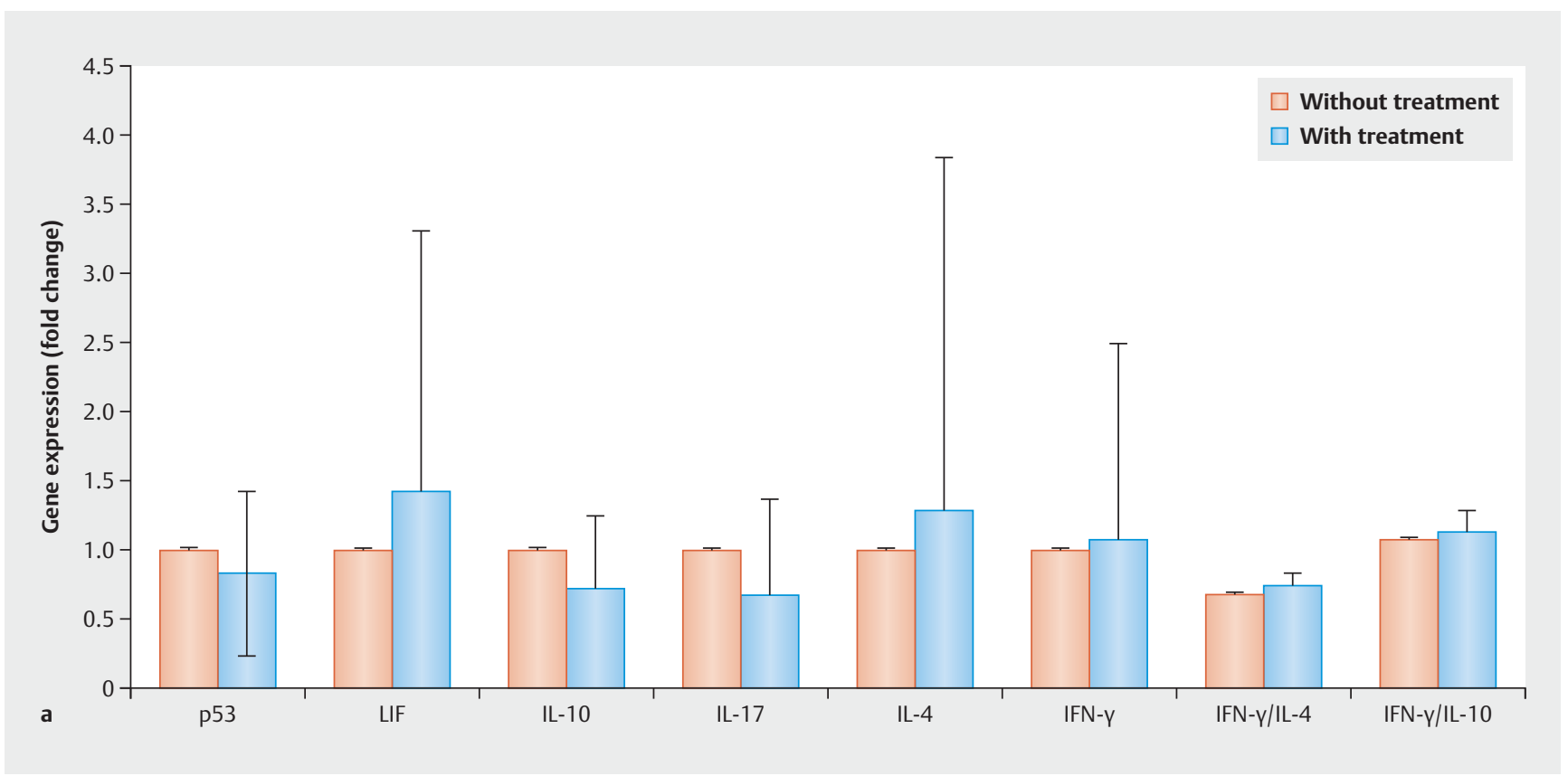

Continued next page 


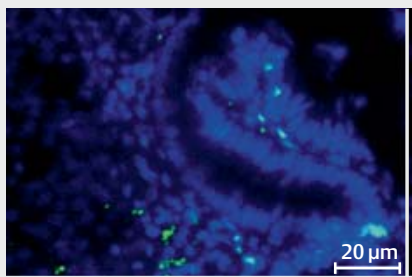

Without treatment

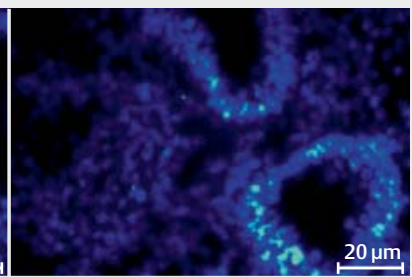

With treatment

LIF

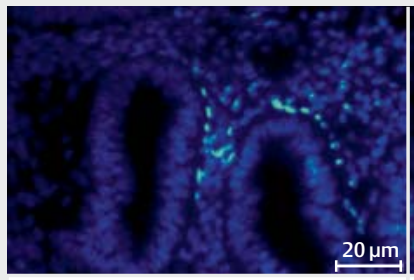

Without treatment

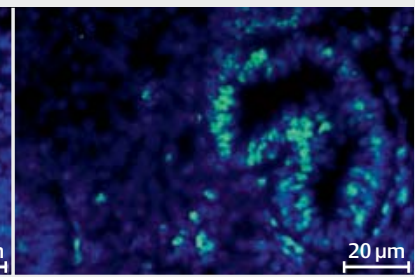

With treatment

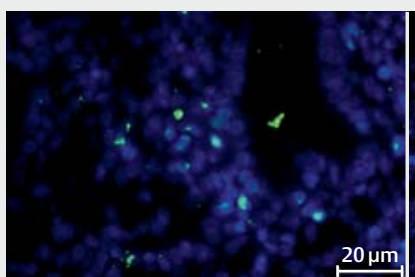

Without treatment

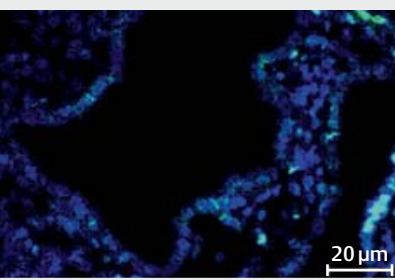

With treatment

IL-10

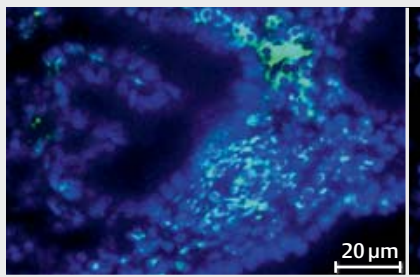

Without treatment

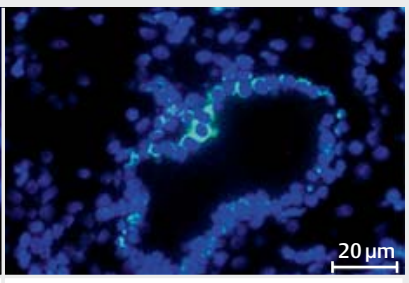

IL-17

IL-4

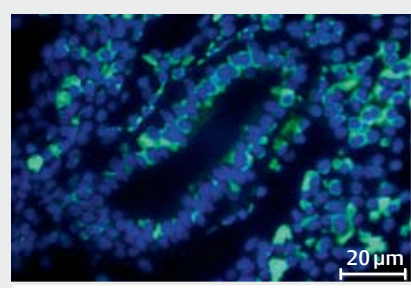

Without treatment

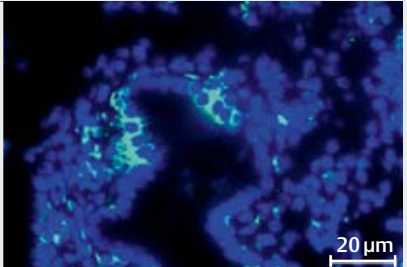

With treatment

IFN-Y

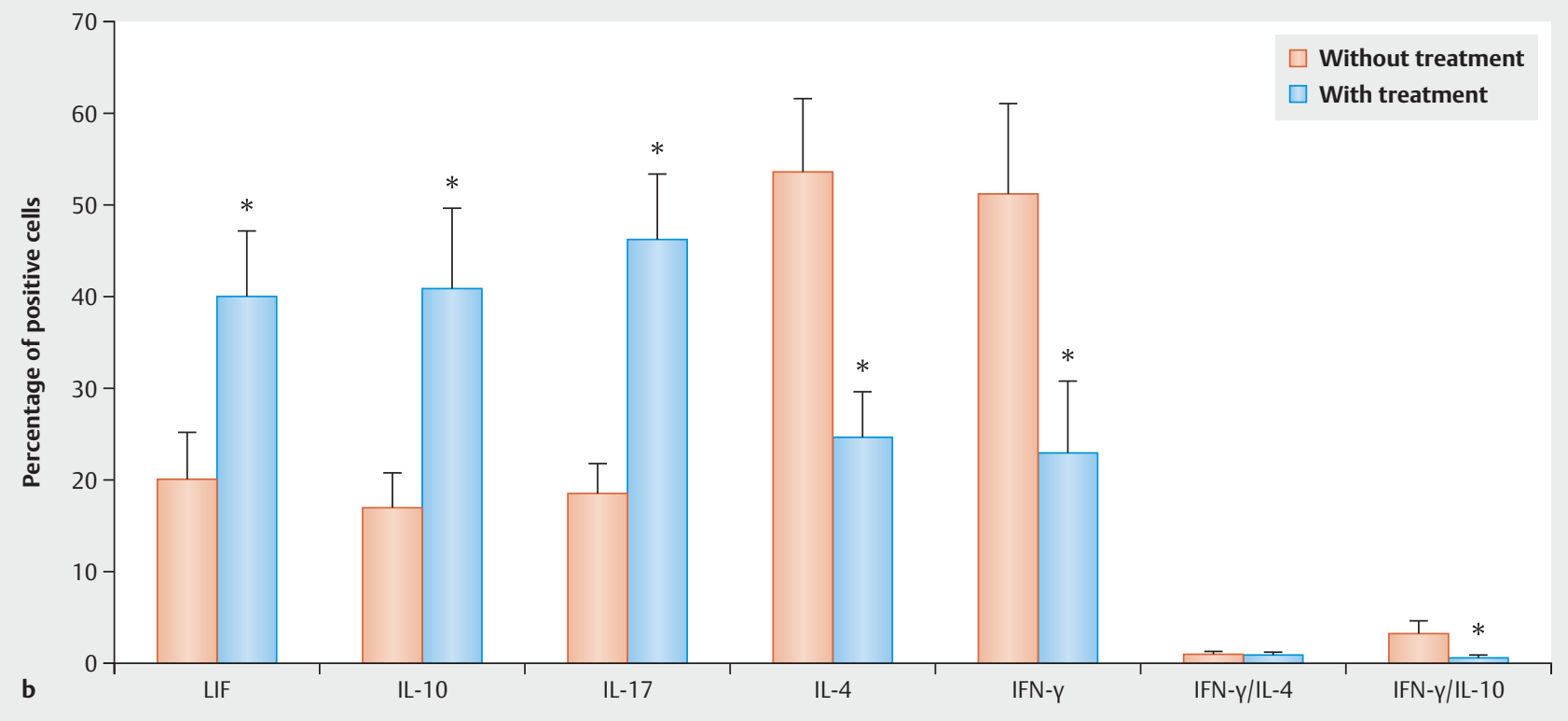

Fig. 2 p53, LIF, IL-10, IL-17, IL-4, and IFN-y, mRNA (a) and protein (b) levels in the endometrial tissue of women with RIF with and without tacrolimus treatment. Fluorescent immunohistochemistry was conducted using primary antibodies against IL-4, IL-10, and IL-17, IFN- $\gamma$, LIF, and fluorescein isothiocyanate-conjugated secondary antibody. Nuclei are stained with DAPI. All images were captured under $400 \times$ magnification. LIF: leukemia inhibitory factor, IL: interleukin, IFN-y: interferon gamma. The nuclei are shown in blue (stained with DAPI) and the evaluated factors in green (fluorescence signals). ${ }^{*}$ = Statistically different in compared to without treatment group. 


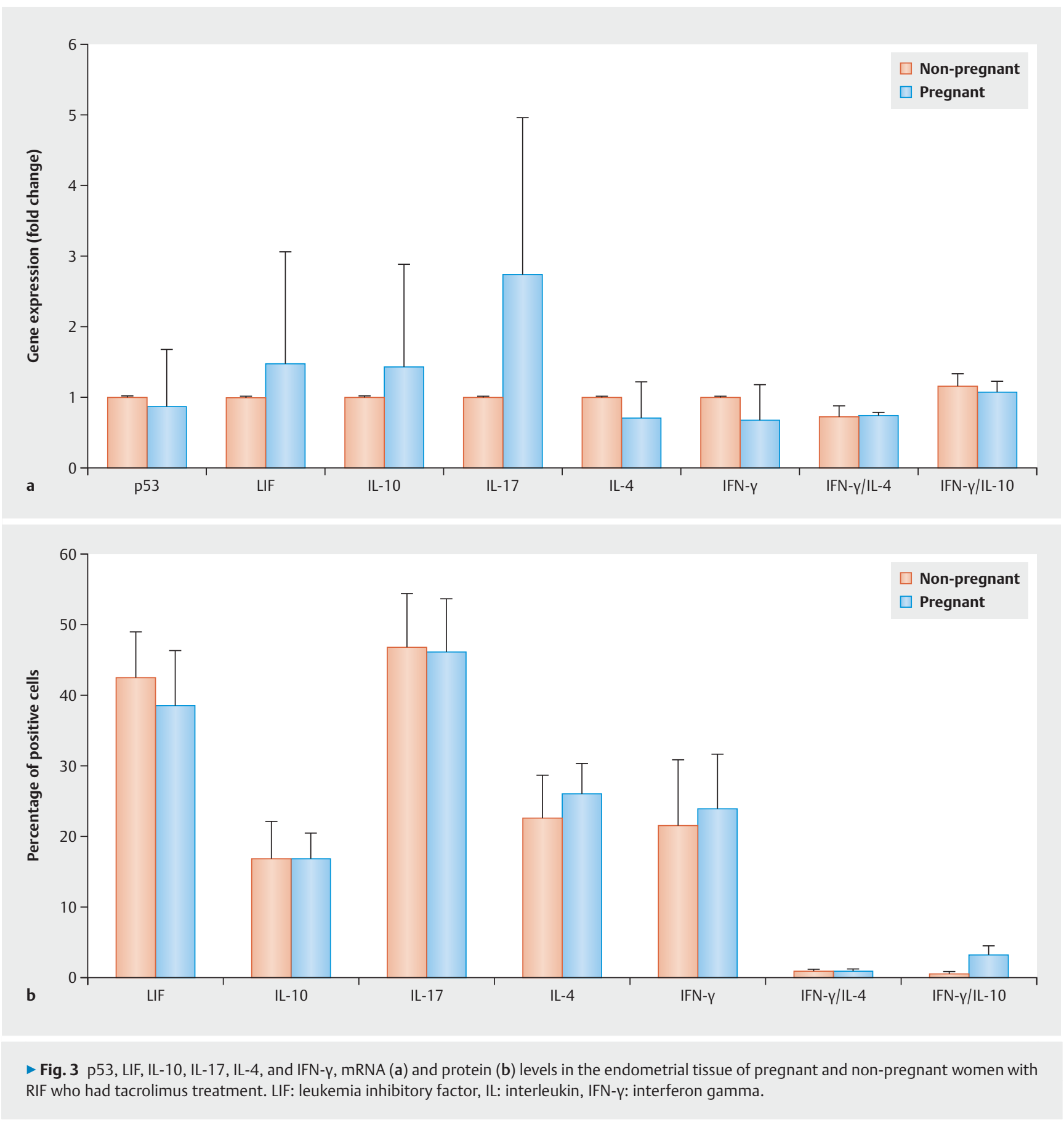

the first description of the effect of tacrolimus on LIF. LIF is a critical parameter in embryonic development and implantation [27, $28]$, trophoblast growth and differentiation [29,30], luminal epithelial pinopode formation [31], and extravillous trophoblast (EVT) invasion [32]. Moreover, LIF enhances decidualization of stromal cells [33] and contributes to the blastocyst hatching process $[34,35]$. The role of LIF in maternal immune tolerance during pregnancy through the regulation of human leukocyte antigen $G$ (HLA-G) [36], which suppresses immune reactions and re-modulates spiral arteries by changing cytokine secretion, consequently facilitates embryo implantation and pregnancy [37]. HLA-G is also involved in establishing a balance between Th1 and Th2 cells that is important for a successful pregnancy [38]. Our data also showed that the mRNA expression of LIF in the pregnant group was higher compared to the non-pregnant group in both tacrolimus treated and non-treated cycles, demonstrating the importance of LIF for endometrial receptivity and embryo implantation. Higher levels of LIF expression were observed in the endometrial tissue of pregnant compared to non-pregnant women during the WOI, and tacrolimus appeared to have a stimulatory effect. Therefore, tacrolimus may improve implantation via the induction of LIF. However, LIF protein levels were lower in pregnant women 


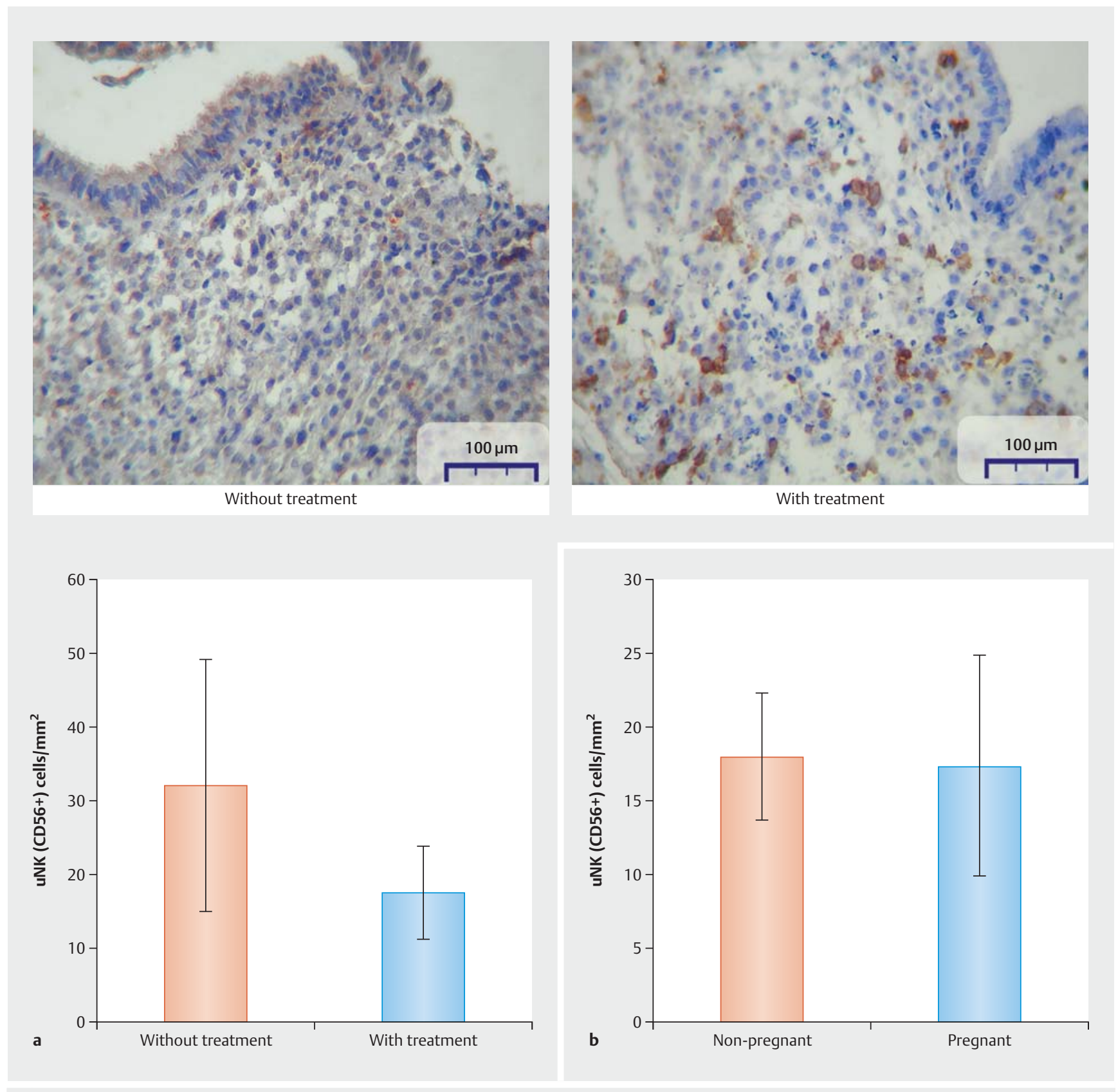

D Fig. 4 Number of uterine natural killer cells (UNKs) in the endometrial tissue of women with RIF. a uNKs in the endometrial tissues with and without tacrolimus treatment. $\mathbf{b}$ uNKs in the endometrial tissues of pregnant and non-pregnant women receiving tacrolimus treatment. Immunohistochemistry staining for CD56+ (a marker of uNKs) allowed for counting per one $\mathrm{mm}^{2}$ of the tissue slide. Scale bars were produced using a morphometric lens ( $\mathrm{CH}-2$, Olympus, Germany) and proofed with Meazure software. All images were captured under $100 \times$ magnification.

compared to non-pregnant women, which could be due to the high rate of LIF secretion into the uterine lumen $[39,40]$.

During pregnancy, the maternal immune system shifts toward the production of Th2-type cytokines such as IL-10 [2,41] in both the maternal circulation and the endometrium. IL-10 plays an important role in maternal immune tolerance $[42,43]$ via several mechanisms, including the inhibition of pro-inflammatory Th1type cytokines (e.g. IFN-y), macrophage production [44, 45], upregulation of soluble HLA-G [46], and the induction of angiogen- esis and placental growth [2]. Interestingly, we found that tacrolimus treatment significantly increased endometrial IL-10, which can improve maternal immune tolerance and the chances of implantation. There are several studies demonstrating elevated IL-10 levels after treatment with immunosuppressant agents such as tacrolimus [47-49].

The role of IL-17 in embryo implantation has not yet been determined. However, due to its pro-inflammatory properties [50], it may have a role in embryo rejection. Since embryo implantation 
- Table 2 Association between embryo implantation rate and cytokine mRNA and protein levels with tacrolimus treatment.

\begin{tabular}{|c|c|c|c|c|c|c|c|c|}
\hline & p53 & LIF & IL-4 & IL-10 & IL-17 & IFN-y & IFN-y/IL-4 & IFN-p/IL-10 \\
\hline \multirow{4}{*}{$\begin{array}{l}\text { Embryo } \\
\text { implanta- } \\
\text { tion rate }\end{array}$} & \multicolumn{8}{|l|}{ mRNA levels } \\
\hline & $\begin{array}{l}r_{s}=-0.351 \\
p=0.394\end{array}$ & $\begin{array}{l}r_{s}=-0.169 \\
p=0.688\end{array}$ & $\begin{array}{l}r_{s}=-0.365 \\
p=0.374\end{array}$ & $\begin{array}{l}r_{s}=-0.052 \\
p=0.902\end{array}$ & $\begin{array}{l}r_{s}=0.266 \\
p=0.524\end{array}$ & $\begin{array}{l}r_{s}=-0.240 \\
p=0.568\end{array}$ & $\begin{array}{l}r_{s}=-0.128 \\
p=0.762\end{array}$ & $\begin{array}{l}r_{s}=-0.247 \\
p=0.556\end{array}$ \\
\hline & \multicolumn{8}{|l|}{ Protein levels } \\
\hline & - & $\begin{array}{l}r_{s}=0.341 \\
p=0.409\end{array}$ & $\begin{array}{l}r_{s}=-0.323 \\
p=0.436\end{array}$ & $\begin{array}{l}r_{s}=0.735 \\
p=0.038\end{array}$ & $\begin{array}{l}r_{s}=0.048 \\
p=0.910\end{array}$ & $\begin{array}{l}r_{s}=-0.219 \\
p=0.602\end{array}$ & $\begin{array}{l}r_{s}=-0.115 \\
p=0.786\end{array}$ & $\begin{array}{l}r_{s}=-0.537 \\
p=0.170\end{array}$ \\
\hline
\end{tabular}

is a semi-allograft, implantation failure may be similar to organ transplant rejection, in which IL-17 plays an important role [15, 16]. On the other hand, IL-17 may pave the way for implantation and pregnancy by inducing angiogenesis [51] and progesterone secretion [52]. We found that tacrolimus significantly increased IL-17 protein levels in the endometrium. However, other studies have reported that tacrolimus and other immunosuppressive agents such as cyclosporine A may decrease IL-17 levels in peripheral blood [20,53-55]. There are no previous reports of the effect of tacrolimus on IL-17 in the endometrium. Interestingly, we found respectively higher and lower mRNA and protein levels of $\mathrm{IL}-17$ in the pregnant group compared to the non-pregnant group, which may be due to the high degradation rate of IL-17 protein in a receptive endometrium or the high rate of IL-17 secretion by the endometrial cells of a receptive uterus. In the present study, both treated and non-treated cycles showed a strong positive correlation between IL-17 and LIF, an important receptivity marker, indicating a positive association between IL-17 and endometrial receptivity. Thus, upregulation of IL-17 following tacrolimus administration in RIF patients could improve endometrial receptivity and, consequently, implantation.

Elevated levels of Th2 cytokines lead to successful implantation, whereas a Th1-dominant environment causes implantation failure [41]. Our study showed that the protein levels of both IL-4 and IFN-y (Th1-related cytokines) significantly decreased following tacrolimus administration. Furthermore, tacrolimus reduced IFN-y/IL-4 and IFN-y/IL-10 ratios, favoring embryo implantation in RIF patients. These findings are aligned with those of other studies which reported an inhibitory effect of tacrolimus on Th1 cytokines [56,57]. In accordance with our results, Nakagawa et al. [8] also stated that tacrolimus could suppress Th1 but not Th2 cells in the uterus. Since we found that in the non-treated cycles the IFN- $/ /$ IL-4 and IFN- $\gamma /$ IL-10 ratios were lower in the pregnant group compared to the non-pregnant group, RIF patients with a low Th1/Th2 ratio may be good candidates for tacrolimus therapy. According to our results, patients with low ratios had better outcomes while tacrolimus was less effective in patients with higher ratios. However, further studies with larger sample sizes are required to define a cut-off value for the ratio as an index figure for tacrolimus therapy.

uNKs are also necessary for the establishment of local maternal tolerance and the survival of the fetus [2]. These cells are different from blood NKs as they have no cytotoxicity potential. uNKs play important roles in the production of Th2 cytokines [18], angiogenic factors, and spiral artery remodeling $[58,59]$. We observed that in the cycle before treatment with tacrolimus, levels of uNKs were higher in the pregnant group compared to the non-pregnant group, hinting at the importance of these cells in endometrial receptivity. The number of uNKs decreased after treatment with tacrolimus. Previous studies have also pointed to a reduction in the number of NKs and the impairment of their function following tacrolimus administration $[60,61]$. Due to a lack of information about the effect of tacrolimus and other immunosuppressive agents on uNKs, it is not known how tacrolimus could decrease the number of uNKs in the endometrium and how such an inhibitory effect might influence implantation and pregnancy rates. Further studies are required to clarify whether a reduction in uNK cells results from tacrolimus treatment and impacts endometrial receptivity and implantation.

To the best of our knowledge, this is the first study to evaluate the effect of tacrolimus on endometrial receptivity, implantation, and pregnancy outcomes. It should be mentioned that our findings demonstrated that tacrolimus significantly affects the protein levels of IL-10, IL-17, and LIF rather than their mRNA expression. There are two possible explanations for this effect. First, tacrolimus could induce translation of the genes mRNAs ro stability of their protein. Secondly, we evaluated the percentage of positive cells for the protein, and it is possible that tacrolimus increases the number of endometrial cells that express these factors instead of increasing the expression of the factors in each cell. However, the main limitation of this study is its small sample size and the unwillingness of patients to undergo two endometrial biopsies. Further studies with larger sample sizes are required to confirm our findings. Moreover, more studies are needed to investigate other immunosuppressive agents such as cyclosporine A or sirolimus and their potential impact for improving implantation rates in RIF patients.

In conclusion, tacrolimus significantly increased the expression of LIF, IL-10, and IL-17 and decreased the expression of IL-4, IFN-Y and the IFN-Y/IL-10 ratio in RIF patients. Tacrolimus treatment led to an implantation rate of $40 \%$, clinical pregnancy rate of $50 \%$ and a live birth rate of $35 \%$ in RIF patients with elevated Th $1 /$ Th2 ratios who had previously failed to become pregnant despite at least three transfers of embryos. Our findings suggest that RIF patients with higher Th1/Th2 ratios could be candidates for tacrolimus therapy. Furthermore, we found a reduced estradiol and proges- 
terone serum levels after treatment with tacrolimus, suggesting that luteal phase support should be considered in the ART cycle of patients receiving tacrolimus.

\section{Acknowledgements}

We would like to thank the staff of Al-Zahra hospital of Tabriz and the Milad Fertility Center for providing the patients and Silvia Perez-Deben and Roberto Gonzalez at IVI Foundation for their help. Also, we wish to thank Dr. Salehpour for her academic advice. Some of the data included are part of the doctoral thesis of Zahra Bahrami-Asl. This study was financially supported by Shahid Beheshti University of Medical Sciences (Grant number: IR. SBMU. MSP.REC.1395.580).

\section{Conflict of Interest}

The authors declare that they have no conflict of interest.

\section{References}

[1] Somigliana E, Vigano P, Busnelli A et al. Repeated implantation failure at the crossroad between statistics, clinics and over-diagnosis. Reprod Biomed Online 2018; 36: 32-38

[2] Lédée $N$, Petitbarat $M$, Chevrier $L$ et al. The uterine immune profile may help women with repeated unexplained embryo implantation failure after in vitro fertilization. Am J Reprod Immunol 2016; 75: 388-401

[3] Coughlan C, Ledger W, Wang Q et al. Recurrent implantation failure: definition and management. Reprod Biomed Online 2014; 28: 14-38

[4] Nakagawa K, Kwak-Kim J, Ota K et al. Immunosuppression with tacrolimus improved reproductive outcome of women with repeated implantation failure and elevated peripheral blood $\mathrm{TH} 1 / \mathrm{TH} 2$ cell ratios. Am J Reprod Immunol 2015; 73: 353-361

[5] Hajipour H, Nejabati HR, Latifi Z et al. Lymphocytes immunotherapy for preserving pregnancy: Mechanisms and Challenges. Am J Reprod Immunol 2018; 80: e12853

[6] Piccinni MP, Lombardelli L, Logiodice $F$ et al. T helper cell mediated-tolerance towards fetal allograft in successful pregnancy. Clin Mol Allergy 2015; 13: 9

[7] Feyaerts D, Benner M, Van Cranenbroek B et al. Human uterine lymphocytes acquire a more experienced and tolerogenic phenotype during pregnancy. Sci Rep 2017; 7: 2884

[8] Nakagawa K, Kwak-Kim J, Kuroda K et al. Immunosuppressive treatment using tacrolimus promotes pregnancy outcome in infertile women with repeated implantation failures. Am J Reprod Immunol 2017; 78: e12682

[9] Mekinian A, Cohen J, Alijotas-Reig J et al. Unexplained recurrent miscarriage and recurrent implantation failure: is there a place for immunomodulation? Am J Reprod Immunol 2016; 76: 8-28

[10] Wilczyński JR. Th1/Th2 cytokines balance-yin and yang of reproductive immunology. Eur J Obstet Gynecol Reprod Biol 2005; 122: 136-143

[11] Rosario GX, Stewart CL. The multifaceted actions of leukaemia inhibitory factor in mediating uterine receptivity and embryo implantation. Am J Reprod Immunol 2016; 75: 246-255

[12] Hu W, Feng Z, Atwal GS et al. p53: a new player in reproduction. Cell Cycle 2008; 7: 848-852

[13] Levine A], Tomasini R, McKeon FD et al. The p53 family: guardians of maternal reproduction. Nat Rev Mol Cell Biol 2011; 12: 259-265

[14] Riley JK. Trophoblast immune receptors in maternal-fetal tolerance. Immunol Invest 2008; 37: 395-426

[15] Afzali B, Lombardi G, Lechler R et al. The role of T helper 17 (Th17) and regulatory $T$ cells (Treg) in human organ transplantation and autoimmune disease. Clin Exp Immunol 2007; 148: 32-46
[16] Heidt S, San Segundo D, Wood KJ. The impact of Th17 cells on transplant rejection and the induction of tolerance. Curr Opin Organ Transplant 2010; 15: 456

[17] Hanna J, Goldman-Wohl D, Hamani Y et al. Decidual NK cells regulate key developmental processes at the human fetal-maternal interface. Nat Med 2006; 12: 1065-1074

[18] Eriksson M, Meadows SK, Wira CR et al. Unique phenotype of human uterine NK cells and their regulation by endogenous TGF-beta. J Leukoc Biol 2004; 76: 667-675

[19] Ledee N, Petitbarat M, Chevrier L et al. The Uterine Immune Profile May Help Women With Repeated Unexplained Embryo Implantation Failure After In Vitro Fertilization. Am J Reprod Immunol 2016; 75: 388-401

[20] Yago T, Nanke Y, Kawamoto $\mathrm{M}$ et al. Tacrolimus potently inhibits human osteoclastogenesis induced by IL-17 from human monocytes alone and suppresses human Th17 differentiation. Cytokine 2012; 59: 252-257

[21] Kino T, Hatanaka H, Miyata S et al. FK-506, a novel immunosuppressant isolated from a Streptomyces. II. Immunosuppressive effect of FK-506 in vitro. J Antibiot (Tokyo) 1987; 40: 1256-1265

[22] Gupta A, Adamiak A, Chow M. Tacrolimus: a review of its use for the management of dermatoses. J Eur Acad Dermatol Venereol 2002; 16: $100-114$

[23] Albaghdadi A], Kan FW. Immunosuppression with tacrolimus improved implantation and rescued expression of uterine progesterone receptor and its co-regulators FKBP52 and PIASy at nidation in the obese and diabetic mice: Comparative studies with metformin. Mol Cell Endocrinol 2018; 460: 73-84

[24] Michel G, Auer H, Kemény L et al. Antioncogene P53 and mitogenic cytokine interleukin-8 aberrantly expressed in psoriatic skin are inversely regulated by the antipsoriatic drug tacrolimus (FK506). Biochem Pharmacol 1996; 51: 1315-1320

[25] Gambichler T, Schlaffke A, Tomi NS et al. Tacrolimus ointment neither blocks ultraviolet $B$ nor affects expression of thymine dimers and p 53 in human skin. J Dermatol Sci 2008; 50: 115-122

[26] Furukawa Y, Yoshikawa $\mathrm{H}$, Iwasa $\mathrm{K}$ et al. Clinical efficacy and cytokine network-modulating effects of tacrolimus in myasthenia gravis. J Neuroimmunol 2008; 195: 108-115

[27] Paiva P, Menkhorst E, Salamonsen L et al. Leukemia inhibitory factor and interleukin-11: critical regulators in the establishment of pregnancy. Cytokine Growth Factor Rev 2009; 20: 319-328

[28] Zollner U, Bischofs S, Lalic I et al. LIF and TNF alpha concentrations in embryo culture media are predictive for embryo implantation in IVF. Asian Pacific Journal of Reproduction 2012; 1: 277-282

[29] Kojima K, Kanzaki H, Iwai M et al. Expression of leukaemia inhibitory factor (LIF) receptor in human placenta: a possible role for LIF in the growth and differentiation of trophoblasts. Hum Reprod 1995; 10: 1907-1911

[30] Sawai K, Matsuzaki N, Kameda T et al. Leukemia inhibitory factor produced at the fetomaternal interface stimulates chorionic gonadotropin production: its possible implication during pregnancy, including implantation period. J Clin Endocrinol Metab 1995; 80: 1449-1456

[31] Aghajanova L, Stavreus-Evers A, Nikas Y et al. Coexpression of pinopodes and leukemia inhibitory factor, as well as its receptor, in human endometrium. Fertil Steril 2003; 79: 808-814

[32] Sharkey A, King A, Clark D et al. Localization of leukemia inhibitory factor and its receptor in human placenta throughout pregnancy. Biol Reprod 1999; 60: 355-364

[33] Shuya LL, Menkhorst EM, Yap J et al. Leukemia inhibitory factor enhances endometrial stromal cell decidualization in humans and mice. PLoS One 2011; 6: e25288

[34] Seshagiri PB, Roy SS, Sireesha G et al. Cellular and molecular regulation of mammalian blastocyst hatching. J Reprod Immunol 2009; 83: 79-84 
[35] Rao RP, Fischer B, Seshagiri PB. Embryo-endometrial expression of leukemia inhibitory factor in the golden hamster (Mesocricetus auratus): increased expression during proestrous and window of implantation stages. Reprod Fertil Dev 2008; 20: 440-449

[36] Bamberger AM, Jenatschke S, Schulte HM et al. Leukemia inhibitory factor (LIF) stimulates the human HLA-G promoter in JEG3 choriocarcinoma cells. J Clin Endocrinol Metab 2000; 85: 3932-3936

[37] Roussev RG, Coulam CB. HLA-G and its role in implantation. J Assist Reprod Genet 2007; 24: 288-295

[38] Fuzzi B, Rizzo R, Criscuoli L et al. HLA-G expression in early embryos is a fundamental prerequisite for the obtainment of pregnancy. Eur J Immunol 2002; 32: 311-315

[39] Licht P, Fluhr H, Neuwinger J et al. Is human chorionic gonadotropin directly involved in the regulation of human implantation? Mol Cell Endocrinol 2007; 269: 85-92

[40] Laird SM, Tuckerman EM, Dalton CF et al. The production of leukaemia inhibitory factor by human endometrium: presence in uterine flushings and production by cells in culture. Hum Reprod 1997; 12: 569-574

[41] Kwak-Kim J, Chung-Bang H, Ng S et al. Increased T helper 1 cytokine responses by circulating $T$ cells are present in women with recurrent pregnancy losses and in infertile women with multiple implantation failures after IVF. Hum Reprod 2003; 18: 767-773

[42] Blanco O, Tirado I, Muñoz-Fernández R et al. Human decidual stromal cells express HLA-G: Effects of cytokines and decidualization. Hum Reprod 2008; 23: 144-152

[43] Maloy KJ, Powrie F. Regulatory T cells in the control of immune pathology. Nat Immunol 2001; 2: 816

[44] Piccinni M-P, Beloni L, Livi C et al. Defective production of both leukemia inhibitory factor and type $2 \mathrm{~T}$-helper cytokines by decidual T cells in unexplained recurrent abortions. Nat Med 1998; 4: 1020

[45] Fiorentino DF, Bond MW, Mosmann T. Two types of mouse T helper cell. IV. Th2 clones secrete a factor that inhibits cytokine production by Th1 clones. J Exp Med 1989; 170: 2081-2095

[46] Criscuoli L, Rizzo R, Fuzzi B et al. Lack of histocompatibility leukocyte antigen-G expression in early embryos is not related to germinal defects or impairment of interleukin-10 production by embryos. Gynecol Endocrinol 2005; 20: 264-269

[47] Caproni M, Torchia D, Antiga E et al. The effects of tacrolimus ointment on regulatory T lymphocytes in atopic dermatitis. J Clin Immunol 2006; 26: $370-375$
[48] Cho ML, Kim WU, Min SY et al. Cyclosporine differentially regulates interleukin-10, interleukin-15, and tumor necrosis factor $\alpha$ production by rheumatoid synoviocytes. Arthritis Rheum 2002; 46: 42-51

[49] Kim W, Cho M, Kim S et al. Divergent effect of cyclosporine on Th1/Th2 type cytokines in patients with severe, refractory rheumatoid arthritis. J Rheumatol 2000; 27: 324-331

[50] Santner-Nanan B, Peek M], Khanam R et al. Systemic increase in the ratio between Foxp3+ and IL-17-producing CD4+ T cells in healthy pregnancy but not in preeclampsia. J Immunol 2009; 183: 7023-7030

[51] Pongcharoen S, Somran J, Sritippayawan S et al. Interleukin-17 expression in the human placenta. Placenta 2007; 28: 59-63

[52] Pongcharoen S, Supalap K. Interleukin-17 increased progesterone secretion by JEG-3 human choriocarcinoma cells. Am J Reprod Immunol 2009; 61: 261-264

[53] Abadja F, Atemkeng S, Alamartine E et al. Impact of mycophenolic acid and tacrolimus on Th17-related immune response. Transplantation 2011; 92: 396-403

[54] Cho ML, Ju JH, Kim KW et al. Cyclosporine A inhibits IL-15-induced IL-17 production in CD4+ T cells via down-regulation of PI3K/Akt and NF-kB. Immunol Lett 2007; 108: 88-96

[55] Zhang C, Zhang J, Yang B et al. Cyclosporin A inhibits the production of IL-17 by memory Th17 cells from healthy individuals and patients with rheumatoid arthritis. Cytokine 2008; 42: 345-352

[56] Grimes PE, Soriano T, Dytoc MT. Topical tacrolimus for repigmentation of vitiligo. J Am Acad Dermatol 2002; 47: 789-791

[57] Grimes PE, Morris R, Avaniss-Aghajani E et al. Topical tacrolimus therapy for vitiligo: therapeutic responses and skin messenger RNA expression of proinflammatory cytokines. J Am Acad Dermatol 2004; 51: 52-61

[58] Croy BA, Esadeg S, Chantakru S et al. Update on pathways regulating the activation of uterine Natural Killer cells, their interactions with decidual spiral arteries and homing of their precursors to the uterus. J Reprod Immunol 2003; 59: 175-191

[59] Goldman-Wohl DS, Ariel I, Greenfield C et al. Tie-2 and angiopoietin-2 expression at the fetal-maternal interface: a receptor ligand model for vascular remodelling. Mol Hum Reprod 2000; 6: 81-87

[60] Tamura F, Masuhara A, Sakaida I et al. FK506 promotes liver regeneration by suppressing natural killer cell activity. J Gastroenterol Hepatol 1998; 13: 703-708

[61] Morteau O, Blundell S, Chakera A et al. Renal transplant immunosuppression impairs natural killer cell function in vitro and in vivo. PLoS One 2010; 5: e13294 